\title{
柔軟振り子の動的線状物体モデリング
}

\section{Dynamic linear object modeling of flexible pendulum}

$\bigcirc$ 学 中西 永 (立命館大) 正 平井 慎一 (立命館大)

Hisashi NAKANISHI, Ritsumeikan University

Shinichi HIRAI, Ritsumeikan University

\begin{abstract}
Soft materials have properties such as passivity, safety and non-holonomic nature. Soft materials have been applied in various areas. However, it is difficult to calibrate soft material parameters. In this paper, we describe a method of viscosity calibration for thin metal materials. We simulate the motion of a flexible pendulum with modeling of linear object deformation. Additionally, we compare experimental and simulation results.
\end{abstract}

key words: Flexible pendulum, Deformable linear object, Material parameter

\section{1.はじめに}

材料の素材を生かしてソフトマテリアルを制御するという 研究が近年盛んに行われている.ソフトマテリアルは材質が 軽量かつ柔軟であるので固いものより, 人や物と接触すると きに安全である. 柔軟な物体は周りの環境に対して形状変化 をすることが可能であり，材料の弾性・粘性要素が高くなり 非ホロノミックな運動となる. 非ホロノミック系の特長とし て劣駆動などが挙げられ，ロボットアームの一部の関節を受 動関節で構成するマニピュレー夕に関する研究 [1] や, 非ホロ ノミックギアによる関節に関する研究 [2] などもある. 他に も, 2 自由度のフレキシブルアームに関する研究も行われて いる [3]. 市川らはマニピュレータの駆動を用いてその挙動か ら紐のパラメータの同定を行っている [4]. 柔軟な物体を扱う 場合には多リンク機構の場合, リンク数に応じた数だけパラ メータの同定が必要になる。これらの柔軟物の動的特性の測 定は容易ではない.

軽量かつ柔軟である条件を満たす材料の一つとして, 薄金 属が挙げられる。金属は延性 (ductile) があり, 素材を薄く 加工するのにすぐれている. また, 機械的な性質として弾性 (elastic), 塑性 (plastic) などがありこれらの性質は材料パラ メータのヤング率 $E$ を用いて物体表面の応力とひずみの関 係を表すことができる.しかし，薄金属の場合は弾性項より 慣性力, 摩擦力などの粘性項の方が支配的になる。一般的に 金属材料のねばさは勒性 (tough) として材料の衝撃的な抵抗 を示すことができる [5]. 弾性・塑性などの要素は静的引張試 験を行えば容易に弾性を表すヤング率 $E$ を求めることがで きる.勒性については材料に動的加重を加える衝撃試験を行 う必要があり, 材料内部の亀裂などが大きく影響するので, 結 果の理論的な扱いは難しい.

そこで本研究では薄金属を片側端点のみを固定し回転に対 してのみ自由な線状振り子を作成した．線状物体モデリング 法 [6][7] を用いて柔軟振り子のシミュレーションを作成した. 線状物体モデルは有限要素法 (FEM) を用いて線状物体を近 似する方法であり, 材料パラメータである曲げ岡性を係数と して表すことができる. 薄金属の動力学的な挙動を観測しシ ミュレーション結果と比較することで, 材料の粘性の導出方 法, 結果との整合性を示す。

\section{2. 柔軟振り子の動力学}

\section{$2 \cdot 1$ 線状物体モデリングとカ学式}

\section{$2 \cdot 1.1$ 線状物体モデリング}

本研究では微分幾何法を用いた線状物体モデルによってシ ミュレーションを作成する. 図 1 に線状物体のモデル図を示 す. 物体の長さを $L$, 原点 $O$ からの距離を $s$ とて任意の点 $P(s)$ を定める. また, 点 $P(s)$ における水平方向からの角度

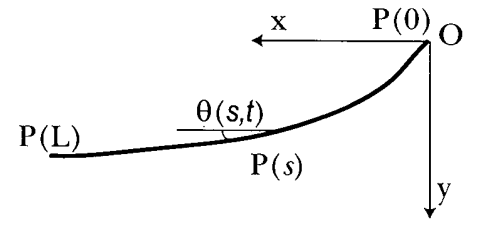

Fig.1 Dynamic deformation of linear object

を $\theta(s, t)$ とし, 時間の関数で表す. 時間 $t$ における点 $P(s)$ の 位置は以下のように表すことができる.

$$
\left[\begin{array}{l}
x(s, t) \\
y(s, t)
\end{array}\right]=\int_{0}^{s}\left[\begin{array}{c}
\cos \theta(u, t) \\
\sin \theta(u, t)
\end{array}\right] \mathrm{d} u .
$$

線状物体の全体の運動エネルギー $T$ を線密度 $\rho$ を用いて表 すと,

$$
T=\int_{0}^{L} \frac{1}{2} \rho\left(\dot{x}^{2}+\dot{y}^{2}\right) \mathrm{d} s .
$$

となる. 全体のポテンシャルエネルギーを $U$ とすると以下の ように表すことができる.

$$
U=U_{\text {flex }}+U_{\text {grav }} .
$$

ただし $U_{f l e x}$ は曲げポテンシャルエネルギー, $U_{\text {grav }}$ は重力 ポテンシャルエネルギーを表す。それぞれ，

$$
\begin{aligned}
& U_{\text {flex }}=\int_{0}^{L} \frac{1}{2} R_{f}\left(\frac{\mathrm{d} \theta}{\mathrm{d} s}\right)^{2} \mathrm{~d} s, \\
& U_{\text {grav }}=\int_{0}^{L} D \sin \theta(s) \mathrm{d} s
\end{aligned}
$$

と表すことができる.ここで, $R_{f}$ は曲げ剛性を表し, 材料の 弾性係数と断面 2 次モーメントから算出可能である. D は物 体の単位質量を表す。ここで, 質点数を $N$ 点として, 質点を 線状物体の原点からの距離 $0 \leq s \leq L$ に等間隔に $\theta_{0} \sim \theta_{N}$ を定めて FEM を用いて質点間を補間する. 以上の $(2),(3)$ 式から $L=T-U$ としてラグランジュ方程式に代入して運 動方程式を求めると以下のようになる.

$$
W \dot{\boldsymbol{\theta}}_{N}-M \ddot{\boldsymbol{\theta}}_{N}+Y \dot{\boldsymbol{\theta}}_{N}-K \boldsymbol{\theta}_{N}-G\left(\boldsymbol{\theta}_{N}\right)=0 .
$$

ここで $\boldsymbol{\theta}_{N}=\left[\theta_{0}, \cdots, \theta_{N}\right]^{\mathrm{T}}$ とし $, W, Y$ は遠心力, コリオリ 力, $M$ は慣性力を表している. また, $K$ は曲げポテンシャル 
エネルギー,$G$ は重力ポテンシャルエネルギーに関する項で ある. 各行列の詳細については文献 [7] を参照されたい. 各 質点の角速度を $\boldsymbol{\omega}_{N}=\left[\omega_{0}, \cdots, \omega_{N}\right]^{\mathrm{T}}$ と定めて式 (6) を変形 すると，

$$
\begin{aligned}
\dot{\boldsymbol{\theta}}_{N} & =\boldsymbol{\omega}_{N}, \\
M \dot{\boldsymbol{\omega}}_{N} & =W \dot{\boldsymbol{\theta}}_{N}+Y \dot{\boldsymbol{\theta}}_{N}-K \boldsymbol{\theta}_{N}-G\left(\boldsymbol{\theta}_{N}\right)
\end{aligned}
$$

と表すことができる. 運動方程式は微分方程式系となるので， Runge-Kutta 法を用いて離散的に状態変数を求める.

\section{$2 \cdot 1.2$ 粘性パラメータの導出}

粘性パラメータとして, 材料の特性である曲げ粘性を $R_{v}$ とすると. 曲げ粘性によるエネルギーの損失 $B$ は，

$$
B=\int_{0}^{L} \frac{1}{2} R_{v}\left(\frac{\mathrm{d} \theta}{\mathrm{d} s}\right)^{2} \mathrm{~d} s
$$

と表すことができる.また, 空気抵抗力を $F_{a i r}$ とすると

$$
F_{\text {air }}=\frac{1}{2} C_{D} v V^{2} S
$$

と表すことができる.ただし,$C_{D}$ は空気抵抗係数, $v\left[\mathrm{Kg} / \mathrm{m}^{3}\right]$ は空気密度, $V[\mathrm{~m} / \mathrm{s}]$ は物体の速度, $S\left[\mathrm{~m}^{2}\right]$ は物体の投影面積 を表す。これらの粘性パラメー夕を式 (8) に導入することに よって粘性パラメータを考慮したモデルが可能となる.

\section{$2 \cdot 2$ 実験結果}

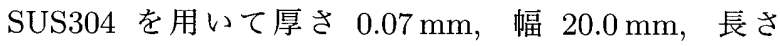
$200.0 \mathrm{~mm}$ の薄金属板を作成した。 その物体を原点のみを固 定して回転運動に対してフリーな機構を作成した. 水平方向 に伸ばした状態から先端位置を離し，その後の挙動を CMOS カメラを用いて 200fps で撮影を行った. 使用した CMOS カ メラには FPGA が搭載されており，高速処理が可能である [7]. 時間間隔 $0.05 \mathrm{~s}$ の形状の変化を図 2 に示す. 線状物体は 剛体ではなく柔軟な弾性体であるので, たわむように形状変 化をしながら特徵的な振り子運動をする.

\section{$2 \cdot 3$ シミュレーション結果}

$2 \cdot 1$ 節で示した運動方程式をもとにシミュレーションを作成 した. 初期条件 $N=5, \boldsymbol{\theta}_{N}=[0,0, \cdots, 0]^{\mathrm{T}}$ として, SUS304 の材料パラメータであるヤング率と断面 2 次モーメントに よって訃算した曲げ岡性 $R_{f}=700 \mu \mathrm{Nm}^{2}$ とした. 曲げ粘性 $B$, 空気抵抗 $F_{a i r}$ を考慮しない柔軟振り子のシミュレーショ ン結果と質点の速度ベクトルを図 3 に示す. 曲げ粘性 $B$, と 空気抵抗 $F_{a i r}$ を考慮したシミュレーション結果を図 4 に示 す. ただし $R_{v}=600 \mu \mathrm{Nsm}, C_{D}=0.6$ と適当な值を代入し た. 実験結果とシミュレーション結果の曲げポテンシャルエ ネルギー $U_{\text {flex }}$ を図 $5, U_{\text {grav }}$ を図 6 に示す.ポテンシャルエ ネルギーの值に関しては各質点の角度 $\theta_{0} \sim \theta_{N}$ をもとに算 出した.

\section{$2 \cdot 4$ 実験結果とシミュレーション結果の比較}

図 2 と図 3 を比較するとシミュレーション結果の振れ幅は 実験の結果より大きくなるが, $0.15 \mathrm{~s}$ までの形状の変化はよ く一致していることが分かる. $0.15 \mathrm{~s}$ 以降においても振れ幅 を考慮せず形状の変化のみに注目すると形状はほぼ一致して

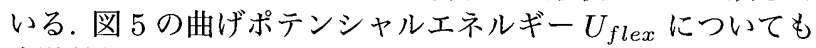
実験結果とシミュレーション結果 case 1 のピーク值の $0.10 \mathrm{~s}$ までのエネルギーの変化はほぼ一致している.

図 2 と図 4 を比較すると図 3 との比較時と同様に $0.15 \mathrm{~s}$ ま での形状の変化はほぼ一致していることが分かる. $0.15 \mathrm{~s} に$ 関しても先端位置の軌道に着目するとシミュレーション結果 と実験結果はほぼ同軌道を描いていることが分かる。また, 図 6 より, 物体の持つ重力エネルギー $U_{\text {grav }}$ の変化が一度エネ ルギーの減衰のピークが $0.25 \mathrm{~s}$ 前後でその後のエネルギーの
回復の傾きがよく一致している. 形状が一致しない原因とし ては質点を代表点による近似で表現しているために複雑な形 状は表現できないということが挙げられる. 質点数を多くす ることによってさらに形状の一致を表すことができると考え られる。

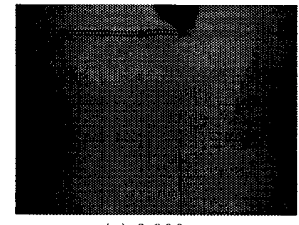

(a) $0.000 \mathrm{~s}$

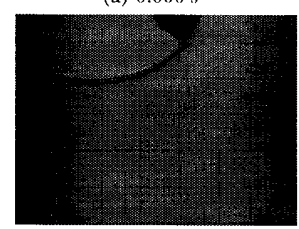

(c) $0.100 \mathrm{~s}$

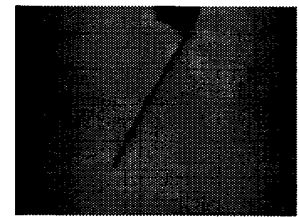

(e) $0.200 \mathrm{~s}$

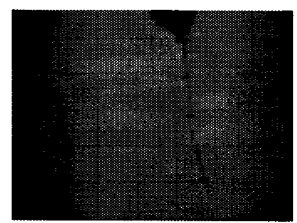

(g) $0.300 \mathrm{~s}$

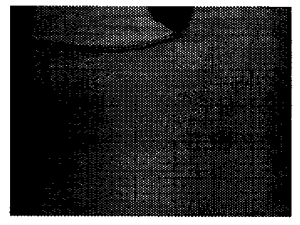

(b) $0.050 \mathrm{~s}$

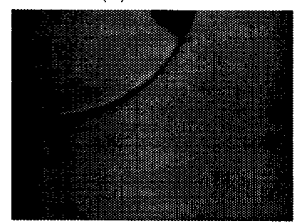

(d) $0.150 \mathrm{~s}$

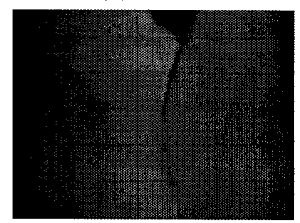

(f) $0.250 \mathrm{~s}$

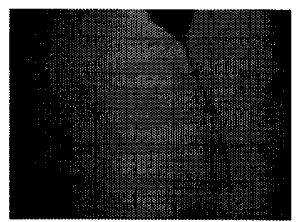

(h) $0.350 \mathrm{~s}$
Fig. 2 Swing motion
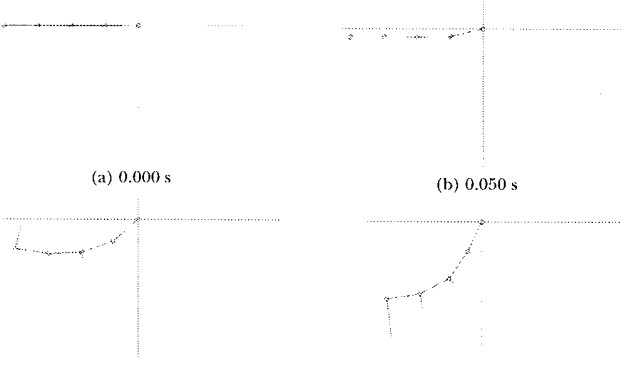

(c) $0.100 \mathrm{~s}$
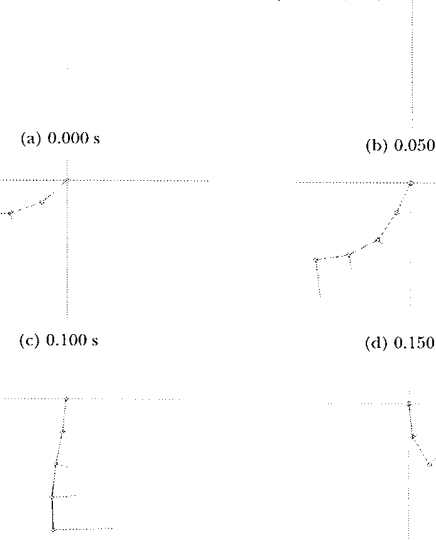

(e) $0.200 \mathrm{~s}$

(f) $0.250 \mathrm{~s}$

(d) $0.150 \mathrm{~s}$

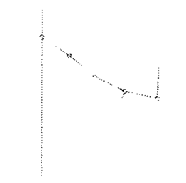

(g) $0.300 \mathrm{~s}$

(h) $0.350 \mathrm{~s}$

Fig.3 Simulation result without bending viscocity or air resistance 


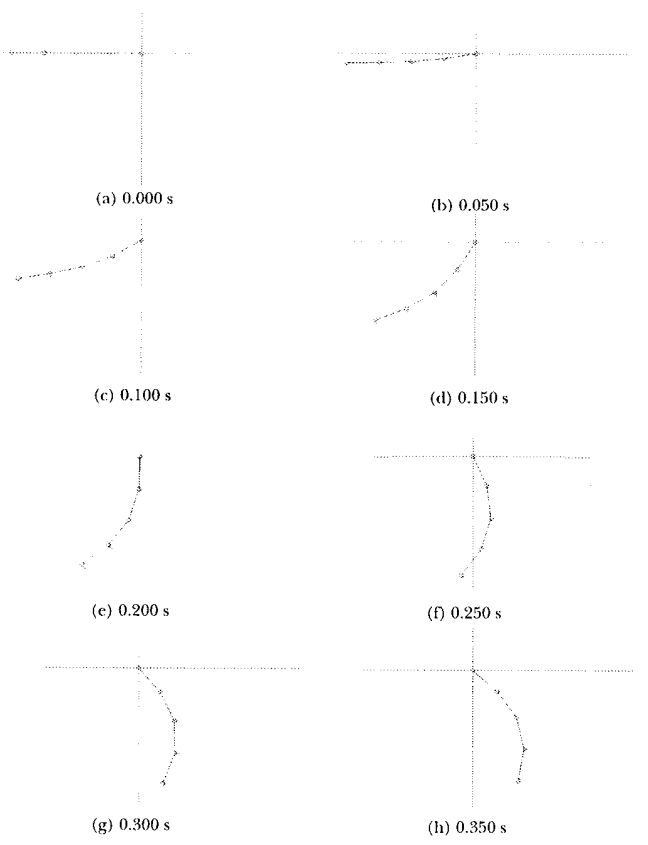

Fig.4 Simulation result with bending viscocity and air resistance

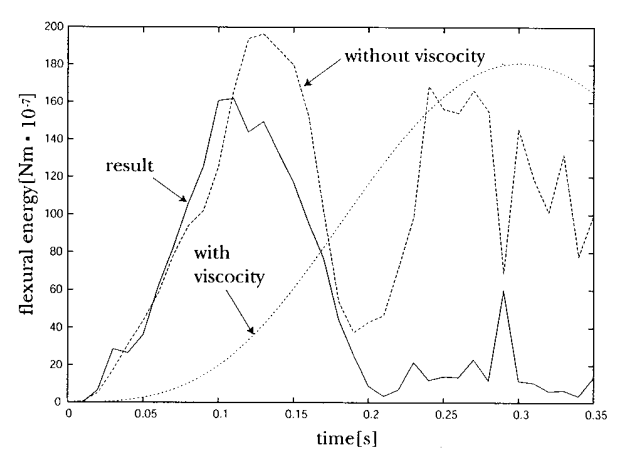

Fig. 5 Flexural energy of flexible pendulum

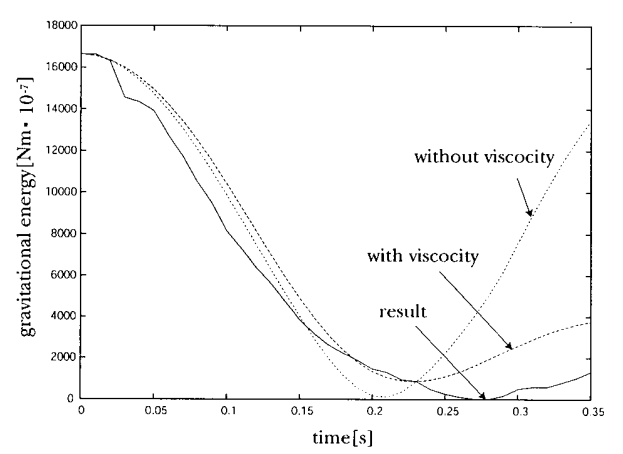

Fig.6 Gravital energy of flexible pendulum

\section{$2 \cdot 5$ 結果の整合性とパラメー夕導出の検証}

$2 \cdot 4$ 節より実験結果とシミュレーション結果が部分的に一 致していることは示された．粘性抵抗 $B$ のみを導入したシ ミュレーション結果を図 7 に, 空気抵抗 $F_{a i r}$ のみを考慮した シミュレーション結果を図 8 に示す。図 3 と図 7 を比べる と曲げ粘性は物体の変形を少なくするように働き，わずかで あるが周期を遅らせていることが分かる. 図 3 と図 8 より空
気抵抗は先端部分に集中して変形していることが分かる.空 気抵抗は速度の 2 乗に比例するので先端部分の方が強く働い ているといえる. 図 9 にシミュレーション結果の運動エネル ギーの比較を示す. 結果的に粘性項の影響によって物体の運 動エネルギーを減衰させている．また，エネルギーの極小値， 極大值の時間的な変化から振り子の周期を遅くしていること が分かる。

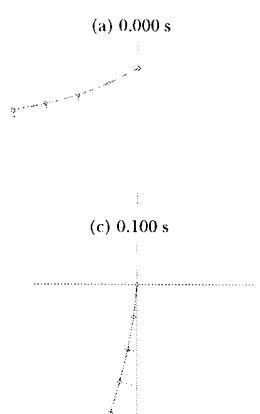

(e) $0.200 \mathrm{~s}$

(g) $0.300 \mathrm{~s}$ (b) $0.050 \mathrm{~s}$

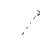

(d) $0.150 \mathrm{~s}$

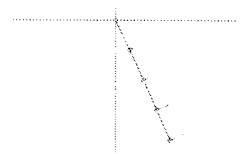

(f) $0.250 \mathrm{~s}$

(t) $0.350 \mathrm{~s}$
Fig.7 Simulation result with bending viscocity and without air resistance (a) $0.000 \mathrm{~s}$

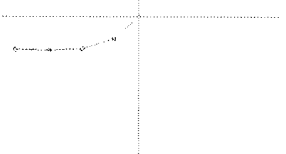

(c) $0.100 \mathrm{~s}$

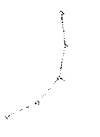

(c) $0.200 \mathrm{~s}$

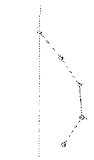

(g) $0.300 \mathrm{~s}$

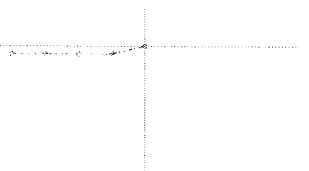

(b) $0.050 \mathrm{~s}$

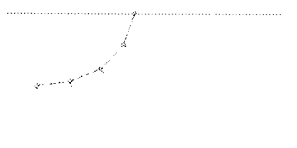

(d) $0.150 \mathrm{~s}$

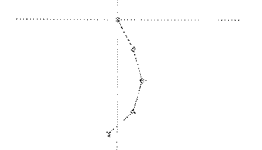

(f) $0.250 \mathrm{~s}$
Fig. 8 Simulation result without bending viscocity and with air resistance 


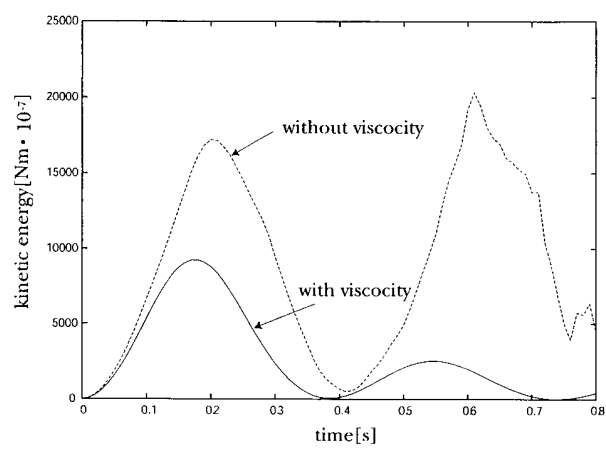

Fig.9 Kinetic energy of flexible pendulum

\section{3. おわりに}

本研究では, 線状振り子を作成して線状振り子の動的な形 状の変化を測定した。線状振り子では㓩体の振り子と違い, 特 有の形状変化が見られた。 また, 線状物体モデリングを用い てシミュレーションを作成した. 実験結果とシミュレーショ ン結果がよく一致していることを確認した。 また, シミュレー ションの粘性項を含む材料パラメータを調節することによつ てシミュレーション結果に変化がみられ, 結果と比較するこ とによってパラメータの同定が可能なことを示した. ポテン シャルエネルギーの数值的な変化に関しては，十分な一致が みられなかった. 今後は求めた材料パラメー夕を用いて柔軟 物体の形状を変化を利用した運動についての検証を行う。

\section{参考文献}

[1] 鈴木高宏, ”非ホロノミック超柔軟マニピュレータ”, 生産 研究, Vol52, No.5, pp237-242, 2000

[2] 中村, 濃沼, 鈴木, ”非ホロノミック・マニピュレー夕の 理論的設計と非線形制御”, 日本ロボット学会誌, Vol13, No.5, pp674-682, 1995.

[3] 吉川, 田村, "フレキシブルアームに対する仮想受動関節モ デルの有効性の検討”, 日本ロボット学会誌, Vol17, No.2, pp250-259, 1999.

[4] 市川, 橋本, ”リンクモデルを用いた紐の動的マニュピ ュレーション”，第 7 回ロボティクスシンポジア，23C3， pp371-376, 2002.

[5] 小原, "金属材料概論", 朝倉書店, 1991.

[6] Hidefumi Wakamatsu, Shinichi Hirai, "Static modeling of linear object deformation based on differential geometry", The International journal of robotic research, Vol23, No.3, pp293-311, 2004.

[7] Hidefumi Wakamatsu, Kosaku Takahashi, Shinichi Hirai, "Dynamic modeling of linear object deformation based on differential geometry coordinates", pro 2005 IEEE, pp1040-1045, 2005. 